\title{
Er staat een olifant in de preventiekamer!
}

\author{
Thomas Plochg
}

Published online: 18 February 2019

(C) The Author(s) 2019

De beweging van nazorg naar voorzorg krijgt steeds meer de wind in de zeilen. Markeringspunten in 2018 zijn het Preventieakkoord, het leefstijlmanifest en het besluit over de geïntegreerde leefstijlinterventie in de basisverzekering. Critici vinden dit (te) kleine stapjes vooruit. De zorg moet nog veel actiever met preventie aan de slag dan ze nu doet. Daarom is het regelen van een goede bekostiging essentieel. Het is aan te bevelen en zelfs urgent om de zoektocht buiten de gebaande paden te vervolgen.

\section{Preventie als B2C}

Wie goed kijkt, ziet dat er een gezondheidsmarkt in opkomst is. Techreuzen als Apple, Google, Alibaba, Amazon, Microsoft en Facebook investeren miljarden in de ontwikkeling van gezondheidsproducten en -diensten op basis van artificial intelligence (AI). Mensen kunnen met deze producten en diensten hun eigen gezondheid monitoren, en - als de belofte wordt ingelost - ook op peil houden. Overigens is deze opkomende gezondheidsmarkt niet louter digitaal. Ook (nieuwe) bedrijven als De Gezonde Zaak, Keerdiabetes2om, Fitchannel, Prescan, Mind\&Health, Visiom, Sense Health, Basic Fit, Hutten Catering, Lifeguard en dergelijke zijn er - soms al jaren - op actief. Zij bieden veelal leefstijlcoaching, sport, catering of andersoortige ondersteuning aan om gezond en fit te blijven.

Twee aspecten van deze opkomende markt verdienen aandacht als het om bekostiging gaat. Ten eerste betreft het een business-to-consumer (B2C) markt. Mensen investeren zelf in hun gezondheid, en willen voor ondersteuning ook betalen, in euro's of des-

\section{T. Plochg $(\varangle)$}

Federatie voor Gezondheid, Utrecht, Nederland t.plochg@nphf.nl noods met hun eigen gezondheidsdata. Ten tweede zijn deze ondernemers for-profit, gericht op het maken van winst. Steeds meer daarvan zijn maatschappelijke ondernemingen die ook willen bijdragen aan een gezonder Nederland.

\section{Disruptief}

Als deze ontwikkeling doorzet, en veel wijst daarop, betekent dit dat preventie niet meer het exclusieve terrein is van de gezondheidszorg. Nieuwe commerciële aanbieders komen met concurrerende alternatieven, die mogelijk aantrekkelijker, beter en goedkoper zijn dan het huidige collectief gefinancierde preventieaanbod. Waarom zouden jonge ouders naar het consultatiebureau gaan als ze online een digitale jeugdarts kunnen raadplegen die meekijkt en hen coacht wanneer het hen uitkomt? Waarom zouden gemeenten een gezondheidsmonitor bij de GGD'en inkopen als de burger realtime zijn eigen gezondheid monitort met zijn mobiele telefoon, en die data plus analyse via een commerciële partij beter en goedkoper verkrijgbaar zijn?

\section{Kansen pakken en publieke belangen borgen}

De opkomende gezondheidsmarkt biedt kansen voor nieuwe vormen van preventie én financiering. Als het mensen daadwerkelijk ondersteunt om gezonder en fitter te leven, dan zal dat op termijn de zorg ontlasten. Mensen benutten dan beter hun zelfhelende vermogen en zelfredzaamheid, en gaan dan minder zorg consumeren. Vanuit maatschappelijk oogpunt is dat wat nodig is. Het levert een gezondere bevolking en lagere zorgkosten op. Een belangrijke kans voor beleidsmakers en bestuurders om de beweging van nazorg naar voorzorg te maken. 


\section{Spectrum}

Toch is het niet vanzelfsprekend dat de commerciële gezondheidsmarkt zijn werkt doet zonder de juiste randvoorwaarden te creëren. Ten eerste bestaat het risico dat het een elitaire markt wordt. Kwetsbare mensen zullen het minst in staat zelf te investeren in hun gezondheid. De grote gezondheidsverschillen nemen dan alleen maar verder toe. Ten tweede is het niet denkbeeldig dat de eerdere genoemde techreuzen de gezondheidsmarkt gaan domineren. Als dat gebeurt, vindt de aansturing (governance) plaats vanuit Silicon Valley of China op basis van winstbejag en aandeelhouderskapitaal, en dus niet meer vanuit de gemeenten op basis van de Nederlandse publieke waarden. Ten derde zullen er gezondheidsondernemers actief zijn die hun verdienmodel baseren op het zogeheten Facebook-model: het doorverkopen van gezondheidsdata aan derden. Dat is onwenselijk. Het resulteert in 'Big Brother is watching your health.' Ten vierde is het belangrijk dat de gezondheidsmarkt niet een marketinginstrument van de zorg wordt, door toegeleiding naar zorg te regelen, wat per saldo juist een hoger zorggebruik oplevert.

\section{Tot slot}

De opkomende commerciële gezondheidsmarkt is de olifant in de preventiekamer. In plaats van te debatteren over hoe preventie binnen het bestaande (eerstelijns)zorgstelsel structureel gefinancierd te krijgen is het noodzakelijk en urgent om na te denken op welke manier public health-belangen geborgd kunnen worden in een samenleving waarin gezondheid een commercieel goed wordt. Dat is niet vrijblijvend. De toekomstbestendigheid van het Nederlandse zorgstelsel hangt er vanaf.

Open Access This article is distributed under the terms of the Creative Commons Attribution 4.0 International License (http://creativecommons.org/licenses/by/4.0/), which permits unrestricted use, distribution, and reproduction in any medium, provided you give appropriate credit to the original author(s) and the source, provide a link to the Creative Commons license, and indicate if changes were made. 